Acta Poetica 31-2

JULIO-DICIEMBRE

2010 (185-207)

\title{
Teología bíblica contextual en América Latina
}

\section{René Krüger}

El artículo destaca que la investigación de los textos bíblicos, tal como la realizan exégetas de las iglesias y facultades de teología del protestantismo histórico en América Latina, tiene referencias socioeconómicas y toma en cuenta el doble marco de la situación social, económica y política en la que se formaron aquellos textos como también la situación actual del continente, pudiendo hablarse de una verdadera contextualización de la exégesis por la pobreza, las diferencias sociales y la historia de la explotación del continente. Una vez constatado ello, el artículo diseña algunas líneas bíblicas fundamentales relacionadas con la ética socioeconómica en un contexto de marginación, opresión y horizontes cerrados. Para ello hace dos recorridos, uno diacrónico, que repasa las grandes etapas de la historia abarcada por los textos bíblicos, y otro sincrónico, repasando los ítems socioeconómicos fundamentales.

PAlabras Clave: exégesis, protestantismo histórico, hermenéutica, situación socioeconómica de América Latina, Biblia y economía.

The article notes that the investigation of biblical texts, as is carried out by exegetes of the Churches and Schools of Theology of historical Protestantism in Latin America, includes socio-economic references and takes into consideration the double framework of the social, economic and political situation in which these texts were created as well as the current situation of the continent. One could speak of a true contextualization of the exegesis by poverty, social differences, and the history of the exploitation of the continent. Once this contextualization is presented, the article designs some fundamental biblical lines related to a socio-economic ethic in the context of marginalization, oppression and closed horizons. To do this, the article 
takes two angles, one is diachronic and reviews the great stages of the history that is covered by the biblical texts, and the other is synchronic and reviews fundamental socio-economic questions.

Key Words: exegesis, historic Protestantism, hermeneutics, Latin America socio-economic situation, the Bible and economics.

Fecha de recepción: 18 de noviembre de 2009.

Fecha de aceptación: 7 de abril de 2010. 


\author{
René Krüger \\ Departamento de Biblia del Instituto Superior \\ Evangélico de Estudios Teológicos \\ Buenos Aires, Argentina
}

\title{
Teología bíblica contextual en América Latina
}

\section{Exégesis y hermenéuticas en América Latina}

El panorama de la exégesis y la hermenéutica bíblicas en América Latina es abigarrado, polifacético, heterogéneo, confuso y sumamente complejo. Abarca desde las posturas más ortodoxas, conservadoras, fundamentalistas y literalistas hasta una serie de posturas para las que la Biblia ya no constituye ningún tipo de referencia ni de importancia para la fe cristiana actual más allá de un mero dato histórico, sometiendo los textos a la más dura y extrema crítica de todo tipo, según la ubicación de quien realiza la lectura. Pasando por supuesto por piedad tradicional de grupos de estudios bíblicos, comunidades de base, lectura comunitaria; pero también la manipulación de textos bíblicos por grupos que sostienen la "teología de la prosperidad"; como también el análisis histórico-crítico y sociopolítico de textos bíblicos, tal como viene siendo practicado por las Iglesias del Protestantismo histórico.

Hablar así de "exégesis o hermenéutica latinoamericana" es una generalización tan difusa e imprecisa como hablar de "fút- 
bol europeo", "comida africana" o "arte australiano". La pregunta planteada con cierta frecuencia desde el hemisferio norte acerca de "LA" exégesis de América Latina puede encerrar así - además de búsqueda auténtica de nuevos caminos de acercamiento a los textos bíblicos- también algún tipo de proyección y acaso un deseo inconsciente por lo exótico (como en su momento sucedió con la construcción europea del "buen salvaje"). Quiero dejar constancia de entrada que no existe "LA" exégesis latinoamericana, sino que hay unas cuantas; y corresponde indicar en cada caso quiénes, qué grupos, corrientes, movimientos o sectores sostienen, elaboran y usan tal o cual dirección interpretativa.

Ahora bien, no es el objetivo de esta breve exposición presentar un panorama de la multiplicidad de posturas y enfoques con los que se analizan los textos bíblicos canónicos del Antiguo y Nuevo Testamento, sino tan solo señalar algunas líneas con las que trabajan la exégesis y la hermenéutica bíblicas comprometidas con la búsqueda de alternativas para los graves problemas socioeconómicos y políticos de América Latina.

En las instituciones teológicas de las Iglesias protestantes y evangélicas históricas se trabaja mayormente con las metodologías exegéticas histórico-críticas, ${ }^{1}$ pero con una diferencia tajante con respecto a su aplicación en Europa, a saber, la depen-

\footnotetext{
${ }^{1}$ Es significativo que las dos instituciones mayores del Protestantismo histórico, el Instituto Universitario ISEDET de Buenos Aires y la Escola Superior de Teologia de São Leopoldo, hayan producido también casi paralelamente sendos manuales de metodología exegética: Wegener, Exegese do Novo; Krüger, Croatto, Míguez, Métodos Exegéticos. Ambos manuales se hallan ampliamente divulgados en todo el continente. Sin ningún tipo de dependencia literaria y ni siquiera de una toma de contacto entre los respectivos autores a la hora de proyectar y escribir los manuales, ambos libros tienen una estructuración y contenidos casi idénticos, tanto en la presentación y ejercitación de la metodología como en el enfoque hermenéutico. Véanse también las referencias a los correspondientes aspectos metodológicos en América Latina en el volumen descriptivo de Hans de Wit, En la dispersión el texto es patria. Introducción a la hermenéutica clásica, moderna y posmoderna (con buena bibliografía).
} 
dencia contextual de la investigación bíblica y un fuerte énfasis en la dimensión sociopolítica, tanto en la investigación de los textos antiguos como en la orientación de quienes los leen hoy. Combinado con ello, se observa una interesante vinculación de la academia con el trabajo eclesial.

Con la calificación de Iglesias protestantes y evangélicas históricas se designan aquellas que tienen sus raíces en el movimiento de la Reforma del siglo XVI en Europa, teniendo, por consiguiente, casi cinco siglos de historia; y que se desprenden de las dos grandes familias teológicas representadas por el luteranismo y el calvinismo. La designación también abarca a las Iglesias con raíces en la prerreforma (Valdenses y Moravos), el Anglicanismo y varias Iglesias de la posreforma (nacidas del movimiento wesleyano). Este protestantismo histórico está representado en América Latina por las siguientes Iglesias: Luterana, Presbiteriana, Reformada, Anglicana, Metodista, Valdense, Congregacional, Discípulos de Cristo, Ejército de Salvación, Bautista, Nazarena, Menonita y otras.

No incluimos en esta breve presentación el análisis de la exégesis católica, que también tiene diversas orientaciones y no se la puede subsumir a una sola línea; pero cabe señalar que unas cuantas investigaciones bíblicas fueron realizadas en conjunto en esfuerzos ecuménicos, sobre todo aquellas que se relacionan con la lectura popular de la Biblia. Por otra parte, debido al empleo de las mismas metodologías de análisis y de orientaciones sociopastorales y teológicas similares enmarcadas en el amplio panorama de la teología de la liberación, una buena serie de productos de estudios bíblicos y de relectura hermenéutica de textos bíblicos evidencia líneas paralelas, como es de esperarse a partir de marcos compartidos.

A mi criterio, la muestra más destacada del trabajo ecuménico de algunos biblistas católicos y unos cuantos protestantes es la publicación RIBLA (Revista de interpretación bíblica latinoamericana). RIBLA se publica ininterrumpidamente desde 
1989, y sus números temáticos son preparados por encuentros regulares en los que se estudia una temática peculiar y se fijan los contenidos de las próximas publicaciones. Es decir, RIBLA es fruto de un trabajo en equipo ecuménico conformado por personas que investigan y escriben situadas en las experiencias de fe y de lucha de las comunidades de las iglesias en dirección a una existencia digna y justa, ${ }^{2}$ empleando para su tarea las diversas metodologías exegéticas en uso, con mayor énfasis en las histórico-críticas por parte de unos y de otros acercamientos, por parte de otros. ${ }^{3}$

En la misma perspectiva ecuménica, con una línea de trabajo centrado en la investigación, la formación y la publicación, pero no solo de la Biblia, se halla el Departamento Ecuménico de Investigaciones (DEI) de San José, Costa Rica. Otro ejemplo destacado de trabajo ecuménico de publicación y formación a nivel de base es el Centro de Estudos Bíblicos (CEBI), con sede en São Leopoldo, Brasil. Ambas instituciones tienen una larga trayectoria y han marcado rumbos claros en el panorama bíblico latinoamericano.

\section{Referencia socioeconómica de la investigación exegética en las Iglesias y Facultades de Teología del Protestantismo histórico}

Un relevamiento terminológico y una revisión temática de trabajos exegéticos latinoamericanos, originados en las institucio-

${ }^{2}$ Destacado así por Milton Schwantes en la presentación del sitio de RIBLA, <http:// www.ribla.org >.

${ }^{3}$ El equipo de RIBLA ha proyectado y editado un número metodológico en el cual se presentan y ponen en práctica diferentes aproximaciones exegéticas y hermenéuticas a un mismo texto, en este caso, Lucas 1-2, evidenciando la enorme riqueza de un panorama que va desde la lectura popular de la Biblia hasta la perspectiva afro-feminista, pasando por el análisis socioeconómico-político, el intercultural, el estructural, el narrativo, el histórico-crítico y el de la hermenéutica del conflicto: RIBLA 53, 2006/1, Interpretación bíblica y busca de sentido y compromiso. 
nes teológicas del Protestantismo histórico, evidencian el peso del contexto actual de América Latina y su historia de cinco siglos de sufrimiento; y a la vez el énfasis en la responsabilidad cristiana por la construcción de un mundo diferente. La terminología es altamente elocuente: opresión, violencia, clientelismo, marginación, globalización, exclusión, neoliberalismo, pobreza, pobres y ricos, los pobres y el reino de Dios, responsabilidad social, fe activa, la fe puesta a prueba, solidaridad, esperanza, compromiso social, actualización del mensaje profético, la dignidad de los pobres, ideología, justicia, avaricia, sociedad de clases, imperio, alternativas, derechos humanos, vida digna, sociedad, política, economía, socialismo, utopía, confrontación, comunidad, el mensaje "escandaloso", la iglesia como comunidad de servicio, radicalismo del Evangelio. El hecho de que este grupo de exégetas se dedique al estudio de textos, preguntas y temas muy específicos, exige un modelo de interpretación. Al buscar puntos de referencia y patrones hermenéuticos, se impone el hecho de que el contexto latinoamericano con sus acuciantes problemas a nivel socioeconómico y político suministra otras prioridades a la exégesis y la teología que se hacen aquí, a diferencia del contexto noratlántico.

Es decir, se puede hablar de una verdadera contextualización de la exégesis por la pobreza, las diferencias sociales y la historia de la explotación del continente. Por consiguiente, los títulos y temas relevados no son eslóganes chillones con los que se rinde un homenaje teológico a una tendencia momentánea. Son antes que nada los problemas y temas sumamente agudos y actuales, que afectan profundamente a los habitantes del continente desde el Río Colorado hasta Tierra del Fuego y del Atlántico al Pacífico. De allí que en la exégesis se noten orientación histórica, predominio del método sociológico en combinación con la exégesis histórico-crítica, esfuerzo por establecer analogías e iluminación del presente por los resultados del análisis del texto bíblico, lealtad hacia un proyecto social utópico con- 
dicionado ideológicamente, optimismo, utopía, relación con la base eclesial, colectivismo, contraste con respecto a la posmodernidad. ${ }^{4}$

La teología latinoamericana subraya que le corresponde una importancia fundamental al lugar desde el cual se realiza la exégesis y la hermenéutica de los textos bíblicos. ${ }^{5}$ Aquí se trata del Sitz im Leben de quienes interpretan el texto, de su lugar y de su participación personal en la vida de la comunidad mayor. Por ello el trabajo teológico también se vincula con la vida entera de la Iglesia. Si bien la historia de las formas enseñó a considerar el Sitz o los distintos Sitze im Leben de los textos, recién el análisis sociológico y político de los textos ha mostrado los lazos muy profundos entre las afirmaciones teológicas y los hechos, las situaciones y las dinámicas de las estructuras sociales, económicas, políticas e ideológicas. Pero nuevamente llevó un buen tiempo hasta que tomaron estado consciente las condiciones previas del lugar propio y de las opciones de los exégetas mismos y la interdependencia de su teología con las estructuras mayores. Ello hace referencia a las estrechas conexiones entre los hechos sociales, la cultura, la religión, el pensamiento, el len-

\footnotetext{
${ }^{4}$ Véase una comparación sumamente instructiva de las exégesis de América Latina con las del ámbito nordatlántico sobre Jueces 4 y 5 en el artículo de Hans de Wit, "Leyendo con Yael". La síntesis de Hans de Wit es lisa y llanamente sobresaliente: "Sin ninguna duda juega un papel aquí la dimensión cultural colectivismoindividualismo, y también el contraste entre modernidad y postmodernidad. A los anhelos latinoamericanos de un nuevo y gran relato, y la confianza en las posibilidad de las personas para tomar parte en él, se contraponen una profunda desconfianza hacia los grandes relatos y la atención por los pequeños pasos y los grandes problemas en la esfera privada de la existencia" ("Leyendo con Yael", 42); y: "Nosotros vemos dos momentos de confrontación que se afirman mutuamente: modernismo versus postmodernismo, y más culturalmente determinado, individualismo versus colectivismo" (49). En breve aparecerá una nueva obra de Hans de Wit sobre la lectura bíblica intercultural, incluyendo prácticas latinoamericanas: Por un solo gesto de amor. Lectura de la Biblia desde una práctica intercultural, Buenos Aires, ISEDET, 2010 .

${ }^{5}$ Véase sobre esta problemática el importante análisis teórico en Boff, Teología de lo politico, 259-319; con énfasis especial en el Sitz im Leben social de la teología.
} 
guaje y la situación personal. ${ }^{6}$ En la investigación de muchos textos, ello lleva a atribuir un peso especial al método sociológico y a colocar un acento peculiar en el relevamiento de los aspectos de la ética social.

Para la teología comprometida con la situación socioeconómica, política e histórica de América Latina, el punto de partida para el registro de la realidad y de las reflexiones teológicas, y por consiguiente también del trabajo bíblico, es, pues, el descubrimiento de las personas marginadas y de las interrelaciones entre la pobreza, el llamado subdesarrollo, la dependencia, el colonialismo, el imperialismo y el actual mercado global al servicio del megacapital; y el compromiso social y político que corresponde a esta toma de conciencia. A nivel teológico se habla aquí también de la "encarnación en el mundo"; pero no de manera abstracta en el mundo en general, sino de la llegada de Dios y de su revelación precisamente allí donde la "lógica de la gloria del mundo" menos las espera: en la pobreza, bajo la opresión, en la marginación. Aquí existen relaciones muy distinguidas con la teología de la cruz del Reformador Martín Lutero, como ha sido señalado ya reiteradas veces por el lado latinoamericano. ${ }^{7}$

Con ello queda abierta la entrada a una importante preocupación de la teología de la liberación: la concientización. ${ }^{8}$ Este concepto desarrollado por el pedagogo brasileño Paulo Freire en los años sesenta se refería por de pronto a la realidad social y económica de América Latina, pero fue asumido muy pronto por la teología. A nivel pedagógico, el concepto halló apli-

${ }^{6} \mathrm{Al}$ respecto, el teólogo católico uruguayo Juan Luis Segundo ha convertido en verdadero programa la necesidad de una "liberación de la teología" en su libro $L a$ liberación de la teología.

${ }^{7}$ Véase una síntesis sobre esta cuestión en Heise, La diaconía de la encarnación, 167-201.

${ }^{8}$ Véase sobre la génesis: Freire, "Conscientização e Alfabetização", 5-24. Y del mismo autor, "Alfabetización de adultos y "concientización"; Cultural Action and Conscientisation; Concientización. Teorías y práctica de la liberación. 
cación sobre todo en el campo de las clases de religión, la catequesis y la educación de adultos. También se ha inquirido acerca de su aplicación para la diaconía o servicio social de las iglesias con el objetivo de aprender como Iglesias a distanciarse de una mera mentalidad de beneficencia y de asistencialismo, para arribar a un verdadero compartir.

En términos cristianos, la concientización no se refiere solo a situaciones o circunstancias externas con respecto al sujeto que conoce, sino que también implica una toma concreta de conciencia de la propia culpa, tanto de la pasiva como de la activa, como por ejemplo la tolerancia frente a la injusticia o la corrupción, el sacar provecho de estructuras injustas y de la explotación de terceros, la negligencia ante atropellos a la dignidad humana.

Sobre este trasfondo y a la vez marco hermenéutico general, podemos diseñar ahora algunas líneas bíblicas fundamentales relacionadas con la ética en un contexto de marginación, opresión y horizontes cerrados.

\section{Textos bíblicos en un contexto económico}

La Biblia contiene numerosos textos sobre la problemática socioeconómica. El marco general, en el que sus autores comprenden y tratan aproximadamente a partir del siglo vIII a. C. esta problemática, puede definirse como la experiencia de la división de la sociedad en pobres y ricos, pobreza y riqueza. $\mathrm{Al}$ respecto, colocan el problema de fondo de pobres y ricos en el marco de una decisión fundamental, que en el Nuevo Testamento queda formulada de manera acertada y tajante como Dios o el Mamón (término de origen arameo que designa dinero). Con ello quedan expuestas dos economías: la economía de lo suficiente para todos y todas, y la economía de la acumulación de la riqueza para algunos pocos propietarios. 
Desde los tiempos bíblicos, la pregunta acerca del origen de la pobreza y de la riqueza ha sido respondida por la clase dominante con una ideología justificadora de los abismos socioeconómicos que veía en la riqueza una muestra de la bendición de Dios. A lo largo de la historia, han sido desarrolladas también definiciones metafísicas adicionales: "Es voluntad de Dios", "Siempre hubo y habrá pobres", "Es el destino", "Es fuerza mayor". Esto llevó a la autojustificación de los ricos y al desprecio de los pobres. En consecuencia, este paquete ideológico descalifica al pobre como haragán, falto de inteligencia e incapaz; y para colmo de males, castigado; en tanto que considera al rico como aplicado, trabajador, exitoso y bendecido. Lo contradictorio es que mientras esta ideología de la bendición, sea religiosa o secularizada, trabaja estos calificativos morales; ella no es capaz de cuestionar éticamente los procederes de la apropiación, la defensa egoísta y la acumulación de la riqueza por unos pocos.

\section{Un recorrido diacrónico por las propuestas bíblicas de ética socioeconómica}

Una excusa sostenida durante mucho tiempo solía afirmar que las propuestas económicas de la Biblia no se podían aplicar en la actualidad, ya que las circunstancias generales de la antigüedad eran totalmente distintas. Esto podrá haber tenido validez para el traslado de elementos del sistema monárquico a la actualidad; pero la investigación socioeconómica evidenció que ya desde el siglo VIII a. C. se desarrolló en toda la región del mundo bíblico una configuración económica de mercado, basada en la propiedad privada en proceso de absolutización, en una economía financiera y de intereses, y en la producción en latifundios con un sistema esclavista (Duchrow, Hinkelammert, La vida o el capital, cap. 1). En tierras bíblicas, la introduc- 
ción de este modelo llevó a un quiebre de la solidaridad de los agricultores y dividió a la sociedad en gente sin tierra y esclavizados por un lado y latifundistas y grandes comerciantes por el otro. A ello se agregó la escisión entre el campo y la ciudad, enriqueciéndose en esta la corte, funcionarios, sacerdotes y posteriormente publicanos. Los imperios helenísticos herederos de Alejandro Magno y luego el imperio romano se basaron precisamente en estos antecedentes.

El capitalismo europeo de la era moderna empalmó con este esquema, agregándole los nuevos medios de producción. Con el desmantelamiento sistémico de la economía social de mercado — allí donde esta pudo desarrollarse - por la imposición global del sistema neoliberal, el mecanismo de la acumulación continuó creciendo cada vez más.

Los diferentes rechazos bíblicos de la opresión, la explotación, la injusticia, la marginación, etc., se dirigen contra las formas aún primitivas de los mecanismos sistémicos de enriquecimiento por un lado y empobrecimiento por el otro. Ahora bien, en los textos correspondientes no se hallan meros juicios ético-morales sobre algunos individuos inmorales, sino juicios sobre los sistemas socioeconómicos como tales, claro está, siempre manejados por individuos.

Para visualizar mejor esta evolución de la crítica que levantan los autores bíblicos frente a los sistemas socioeconómicos productores de personas pobres y marginadas, es importante tener presente la siguiente evolución cronológica de la historia de Israel: ${ }^{9}$

1. Luego de la liberación del sistema político-económico del trabajo forzado en la esclavitud bajo el faraón "divino" y en la época anterior a la constitución nacional de Israel (1250 a 1000

${ }^{9}$ Sobre cada uno de los ítems enumerados a continuación, hay una amplísima literatura cuya mención llenaría páginas y más páginas. Remitimos simplemente a un pantallazo general en Duchrow, Alternativas al capitalismo global-extraídas de la historia bíblica y diseñadas para la acción política, parte II. 
a. C.), se buscó construir una alternativa "nacional" bajo la voluntad de Dios, en el sentido de la conservación de la libertad, y caracterizada por la solidaridad familiar y tribal mediante la independencia e incluso la oposición regional y estructural a los grandes imperios del antiguo Cercano Oriente construidos sobre la esclavitud y altos tributos.

2. En la época de los reyes del reino único y luego dividido (1000 hasta 586 a. C.), se intentó "disciplinar" o "domar" mediante leyes la economía de la propiedad y el sistema real, cuestionado por muchos en Israel. El Salmo 24: 1 subraya enfáticamente: Del Señor es la tierra y su plenitud, el mundo y los que en él habitan. La idea central es que la tierra en sí, juntamente con toda la humanidad, es propiedad de Dios; y que Dios entrega la tierra a la humanidad para que esta pueda vivir de la misma. Si el Salmo lo subraya tan enfáticamente, es porque debió enfrentarse con quienes pretendían ser dueños de la tierra y de sus habitantes. En efecto, desde el siglo vIII a. C. diversos textos bíblicos discutían sobre la cuestión de la propiedad debido a que en ese momento se había originado en Grecia una nueva modalidad económica basada en la propiedad privada y en la práctica de la cobranza de intereses, que se extendió rápidamente por todo el Antiguo Cercano Oriente. Los préstamos debían ser garantizados mediante la propiedad del deudor. Si este por una mala cosecha u otro contratiempo no podía devolver lo que había pedido prestado, perdía su tierra y en ocasiones su propia libertad. Esto llevó rápidamente a una escisión en el cuerpo social, aumentando por un lado los latifundistas y por el otro los pobres, los sin tierra y los esclavos. Juntamente con estos mecanismos se desarrolló el dinero, no solo para posibilitar el intercambio comercial y el pago de las deudas, sino también la acumulación de la riqueza.

Este proceso suscitó la crítica profética dirigida contra los excesos del poder, la explotación económica de los débiles, la acumulación ilimitada de propiedades ( $c f r$. Isaías 5: 8) y el sis- 
tema en sí. Fue en esta época que las reformas legales de la Ley hebrea, la Torá, proporcionaron claras contramedidas estructurales y leyes preventivas (Éxodo 22: 24: prohibición de tomar intereses por préstamos) frente a los mecanismos socioeconómicos que se iban desarrollando, relacionadas fundamentalmente con el régimen de préstamo a interés y la esclavitud por endeudamiento; queriéndose revertir la inversión del circuito de la bendición mediante leyes económicas y sociales preventivas y correctoras para proteger a quienes se empobrecen.

3. En la época exílica y persa ( 586 a 333 a. C.), Israel reflexionó profundamente sobre cómo vivir según los mandamientos de su Dios Yavé dentro del nicho que le permitía ocupar el imperio, esforzándose por construir alternativas frente a la normalidad del Oriente antiguo, y formando una especie de "República de la Torá" en el marco del imperio persa.

4. En la época de los imperios totalitarios, primero el helenístico y luego el romano, a partir del 168 a. C. se desarrollaron formas de resistencia y de esperanza en el reino de Dios que se concebía con cara humana y como superador de los imperios. Diversos grupos intentaron desenmascarar el carácter antidivino de los grandes reinos o imperios helenístico-romanos y pasaron a la resistencia contra la imposición totalitaria de su economía financiera y de propiedad, que además amenazaba con destruir la identidad religiosa judía. Las propuestas de estos grupos se hallan en los escritos apocalípticos de la época intertestamentaria. Allí también surgió con nitidez la fe en el juicio final con su doble resultado de resurrección para la vida eterna de los fieles a la Ley de Dios y para el castigo eterno de los transgresores impíos. Jesús y la primera Iglesia cristiana participaban en este amplio movimiento contracultural y contrahegemónico. En el caso de Jesús, se agrega la convicción de que también bajo las circunstancias históricas más adversas el reino de Dios ya va construyendo a nivel microsocial pequeñas alternativas mediante comunidades mesiánicas, que son espa- 
cios de contención para personas marginadas, empobrecidas y despreciadas.

Un recorrido sincrónico por la cuestión socioeconómica en la Biblia

A los efectos de completar el panorama de la ética socioeconómica de la Biblia, es importante trazar también las principales líneas sincrónicas de la materia.

1. Ambos relatos fundantes transmitidos por la Biblia Hebrea, a saber, el éxodo de la esclavitud de Egipto y la creación, colocan ideas centrales sobre la temática socioeconómica. En el éxodo, Dios libera a su pueblo de la opresión y convierte a las personas en "propietarias de sí mismas", por así decirlo. Aquí aparece la semilla de la idea de la dignidad del trabajo, vinculada a su vez con la dignidad y la necesidad del descanso. El Éxodo es un rotundo NO de Dios a todo trabajo forzado, esclavizante e indigno.

2. En el Génesis, el ser humano es presentado como a imagen y semejanza de Dios. Esta noción incluye la función de ser representante de Dios; y ello tiene implicancias directas con relación a los bienes, pues abarca la correcta administración de los recursos en beneficio de toda la comunidad humana. La tierra y sus recursos son entregados por Dios a la humanidad — representada en Adán y Eva - para su cuidado y trabajo.

Esto es recordado en diversas celebraciones del pueblo de Israel vinculados con el comienzo y fin de la cosecha de cereales y la vendimia. Las ofrendas y el diezmo representan una devolución de lo recibido a quien lo da. La referencia a Dios como dador de los bienes abre la mente para el servicio al prójimo e implica transferencias solidarias para los pobres. Quien concibe sus bienes como regalo, los puede compartir con otros. 
3. El año sabático (Éxodo 23: 10-11; Levítico 25: 1-7) y el jubileo (Levítico 25: 8-55) tienen su fundamento en la misma idea básica de la tierra como propiedad de Dios. Ambas instituciones marcan el comienzo de una legislación social. Ponen límites a la explotación de la tierra al exigir el descanso de los campos, apuntan a la libertad de las personas disponiendo la liberación de los esclavos y buscan una redistribución justa de las propiedades mediante la restitución a sus dueños originales. Todo ello constituye una limitación temporal de las propiedades. La intención y los efectos sociales de estas medidas son absolutamente claras: los bienes regalados por Dios a sus criaturas deben suministrar suficiente alimento a todos y no un exceso a unos y miseria a otros.

4. Numerosos textos legales y proféticos contienen disposiciones muy concretas relacionadas con la justicia en el trato de los asalariados y jornaleros y con las relaciones económicocomerciales. Insisten en jornales justos y pagos en fecha (Levítico 19: 13; Deuteronomio 24: 14-15; Malaquías 3: 5; Jeremías 22: 13) y en balanzas, pesas y medidas justas (Levítico 19: 3536; Deuteronomio 25: 15; Proverbios 11: 1; 16: 11; 20: 10; Miqueas 6: 10-12).

5. Los textos proféticos instalan una restricción social de la propiedad. La crítica social de los profetas se levanta contra la ideología de la riqueza como bendición; denuncia enérgicamente la explotación, la injusticia, la corrupción; y exige la atenciónde las viudas, los extranjeros, los huérfanos y los pobres, es decir, de las personas marginadas y más débiles de la sociedad (cfr., p. ej., Isaías 1: 5; 3: 15; 5: 8-9; 10: 2-3; Jeremías 22: 13-14; 39, 10; Amós 2: 6-8; 4, 1; 5: 11-12; 6: 1-9; 8: 4-6. Cfr. también Henoc etiópico [escrito intertestamentario pseudoepigráfico, no canonizado] 94: 8-11; 96: 4-5; 97: 8-10; 103: 5-8). Esto evidencia que el criterio ético para el correcto uso de las posesiones consiste en la atención y la inclusión de los miembros más desprotegidos del cuerpo social. 
6. A ello se agrega la sabiduría del antiguo Israel, plasmada en diversos escritos como Proverbios, Eclesiastés, Sabiduría, Eclesiástico y otros, que insiste en la precariedad de todo quehacer humano y en el carácter transitorio de la riqueza y todos los bienes de la vida; y a la vez insiste en el sometimiento a la ley de Dios.

7. Diversos textos, sobre todo proféticos y legales, también desenmascaran la manipulación corrupta de la justicia por parte de quienes detentan el poder.

8. Jesús profundizó la visión socioeconómica altamente crítica de los profetas frente al dinero y la riqueza. El énfasis colocado en el anuncio del Evangelio a los indigentes, las bienaventuranzas de los pobres y los ayes contra los ricos, la polémica contra el Mamón y los privilegios de los ricos en la sociedad, los actos de solidaridad concreta con los pobres, los dichos sobre la oposición entre el tesoro celestial y los tesoros terrenales, la advertencia ante los peligros de la riqueza y la avaricia, la exhortación a ser rico en Dios, todo esto crea una inversión de los valores marcados por el dinero, la riqueza y el estatus.

La síntesis de la postura de Jesús queda expresada en dos frases: Miren, guárdense de toda avaricia, porque la vida del hombre no consiste en la abundancia de los bienes que posee (Lucas 12: 15); y Ninguno puede servir a dos señores, porque odiará al uno y amará al otro, o estimará al uno y menospreciará al otro. No pueden servir a Dios y a las riquezas (о: al Mamón, Mateo 6: 24 y también Lucas 16: 13). Múltiples palabras de Jesús enseñan que la vida gana profundidad si las personas comparten lo que tienen, en beneficio del bien de todos y principalmente de los miembros débiles de la sociedad.

Dos libros neotestamentarios en especial, el Evangelio de Lucas y la Epístola de Santiago, ${ }^{10}$ evidencian un alto grado de preo-

${ }^{10}$ Nos permitimos remitir a dos estudios propios sobre el tema: René Krüger, Pobres y ricos en la epístola de Santiago. El desafio de un cristianismo profético, 
cupación de sus respectivos autores por las situaciones de injusticia y marginación de sus comunidades; y manifiestan un decidido compromiso con la justicia social, la inversión de valores y la solidaridad con los pobres. Contienen duras palabras de juicio y amenaza contra los ricos egoístas y derrochadores, los acaparadores, los terratenientes insensibles y explotadores. Demuestran, por ejemplo, que lo que se juega en el latifundio y en el acaparamiento no es una racionalidad económica, que en algún momento supuestamente traerá beneficios para todos, sino más ganancia para los ricos, una economía salvaje del beneficio propio, el lucro personal, el acaparamiento, el derroche y la dolce vita por un lado; y por el otro, pérdidas para aquellos que de por sí ya sufren carencias de todo tipo.

9. Los festines de los ricos son la cara visible y lúdica de otra faceta más de su pecado: la ociosidad. Esta haraganería entretenida se opone a la necesidad constante de trabajar, sembrar, arar, cosechar, tal como la vivía todo obrero, pequeño agricultor y peón rural con su familia. Con su estilo de vida, el ocioso se convierte en parásito, que hace que otros trabajen por él.

10. La pobreza tiene sus causas estructurales en la injusticia, la violencia y el abandono de las leyes de Dios. Las disposiciones bíblicas en general y el programa de reformas del Deuteronomio en especial son muestras del esfuerzo por llevar esta visión a la conciencia y la práctica de todo el pueblo de Israel. Dios quiere que aquellos que forman su pueblo vivan de manera diferente; incluyendo y no excluyendo a las personas, protegiendo y no explotando al prójimo, sanando y no enfermando, dando vida y no matando, perdonando y no tratando con injusticia.

Allí donde son explotados los pobres, donde los opulentos derrochan las riquezas y donde no se comparten los bienes, la

y Dios o el Mamón. Análisis semiótico del proyecto económico y relacional del Evangelio de Lucas. 
riqueza se relaciona estrechamente con el pecado. La riqueza acaparada por unos pocos no mantiene ni aumenta la calidad de vida, sino que provoca la muerte de los pobres y la condena eterna de los ricos egoístas a causa de pecados económicos y sociales muy concretos: acaparamiento, codicia, acumulación egoísta de riquezas, explotación de los trabajadores, glotonería, derroche, crueldad, manejo corrupto de la justicia. Dios juzga y condena a quienes despliegan esas conductas antisociales, injustas, explotadoras y violentas.

\section{Sintesis}

La teología y la exégesis críticas de la situación socioeconómica y política, desarrolladas tanto en América Latina como también en otras regiones del mundo, subrayan enfáticamente que el testimonio bíblico es totalmente diáfano: Dios está del lado de los débiles, pobres, perseguidos, dolidos, marginados, despreciados y necesitados. Quien peca contra ellos, produciendo esas situaciones miserables o dejándolos sumidos a los necesitados en las mismas, peca contra el Dios viviente. De allí que Dios sea el abogado de los maltratados, el defensor de las personas más débiles del cuerpo social: huérfanos, viudas, extranjeros, jornaleros, hambrientos, enfermos.

Enel orden antropológico y teológico, la Biblia enfatiza la dignidad de los pobres y la decidida acción de Dios a favor de ellos, mostrando su elección y el valor de la comunidad de contención. La dignidad del ser humano no se deriva de la cantidad de bienes acumulados ni consiste en llenarse de riquezas o codiciar lo imposible pasando por encima las necesidades del prójimo. La dignidad consiste en ser hija, hijo de Dios, y en poner en práctica el mandato del amor. Esta convicción básica de que todo ser humano es criatura de Dios es el móvil más fuerte para la decidida acción social de las Iglesias cristianas. 
La propuesta económica de la Biblia consiste en una economía del compartir, que posibilita y fomenta la vida; y que se contrapone a la economía salvaje del beneficio propio, basada en la explotación de otras personas. La especulación, el acaparamiento, el derroche y la dolce vita tiene una racionalidad materialista y especulativa propia, que desde la óptica de Dios se evidencia como necedad, tal como lo expresa la parábola del rico necio (Lucas 12: 13-21). La economía del compartir no implica la anulación de la propiedad, el dinero o los bienes; sino que subraya enfáticamente la función social de los bienes, el dinero y la riqueza. Esta función social consiste en garantizar, mantener y mejorar la vida de todo el cuerpo social, y no solo de una parte del mismo.

La perspectiva ética socioeconómica de la Biblia es la perspectiva de las víctimas; de aquellas personas que son subyugadas, empobrecidas y marginadas por otras personas. Es hermenéutica —interpretación de la realidad- "desde abajo"; precisamente con comillas, pues una adopción directa de la formulación "desde arriba" o "desde abajo" también podría implicar la aceptación de la valoración ideológica implícita de las personas y los grupos sociales designados.

Una teología crítica actual no puede sino asumir esta perspectiva de las víctimas, pues solo con ella es posible comprender los textos que fueron escritos a partir de esas experiencias; y solo así podrá tratarse de formular evaluaciones y propuestas válidas para la situación actual. A partir de la opción decidida de Dios por las víctimas, el cumplimiento de sus mandatos es expresión de la libertad humana, fundamentada en la acción liberadora de Dios a favor de su pueblo y su humanidad.

No está de más decir que la producción teológica, exegéticohermenéutica realizada desde esta perspectiva desde las víctimas, los débiles y los que sufren, vinculada con un trabajo sólido sobre los textos bíblicos, que emplea tanto las metodologías exegéticas ya consideradas "clásicas" como también las nue- 
vas aproximaciones desde lo sociológico, económico, político, antropológico, cultural, la perspectiva de género, lo estructural, lo narrativo, etc., ha llamado la atención mucho más allá de las fronteras culturales e idiomáticas de América Latina, y ha comenzado a producir un diálogo interesante con la exégesis y la hermenéutica del hemisferio norte. ${ }^{11}$ Un desafío significativo que aún tenemos por delante es el diálogo fructífero con líneas similares de África, Asia y Oceanía.

\section{REFERENCIAS}

Boff, Clodovis, Teología de lo político. Sus mediaciones, Salamanca, Sígueme, 1980 [versión castellana de la edición portuguesa de la disertación francesa: Théologie et libération. Questions d'épistémologie, Lovaina, 1976].

Duchrow, Ulrich, Alternativas al capitalismo global - extraídas de la historia bíblica y diseñadas para la acción política, parte II, Quito, ABYA-YALA, 1998.

Duchrow, Ulrich y Franz J. Hinkelammert, La vida o el capital. Alternativas a la dictadura global de la propiedad, San José, Costa Rica, DEI, 2003.

FreIre, Paulo, "Conscientização e Alfabetização — uma nova visão do processo", en EU (Pernambuco, Brasil), 4, 1963, 5-24.

${ }^{11}$ Muestra evidente de ello son las participaciones de exégetas de América Latina en los encuentros teológicos y exegéticos y sus abundantes publicaciones en el hemisferio norte, como también las obras conjuntas de biblistas de ambos hemisferios, de cuya gran cantidad permítaseme brindar apenas cuatro ejemplos: Ross Kinsler y Gloria Kinsler (eds.), God's Economy. Biblical Studies from Latin America; Ulrich Schoenborn (ed.), Wege des Verstehens. Beiträge zu einer interkulturellen Hermeneutik; Daniel Patte (ed.), Global Bible Commentary (con comentarios sintéticos de todos los libros bíblicos elaborados por biblistas de todo el mundo, entre ellos, dieciocho de América Latina); Erhard S. Gerstenberger y Ulrich Schoenborn (eds.), Hermeneutik-sozialgeschichtlich. Kontextualität in den Bibelwissenschaften aus der Sicht (latein)amerikanischer und europäischer Exegetinnen und Exegeten. 
FreIRE, Paulo, “Alfabetización de adultos y 'concientización", en Mensaje, Sept. 1965.

FreIRE, Paulo, Cultural Action and Conscientisation, Santiago, UNESCO, 1968.

FreIRE, Paulo, Concientización. Teorías y práctica de la liberación, Buenos Aires, Búsqueda, 1974.

Gerstenberger, Erhard S., y Ulrich Schoenborn, (eds.), Hermeneutik-sozialgeschichtlich. Kontextualität in den Bibelwissenschaften aus der Sicht (latein)amerikanischer und europäischer Exegetinnen und Exegeten, Münster, Lit Verlag, 1999.

Hansen, Guillermo (ed.), Los caminos inexhauribles de la Palabra. (Las relecturas creativas en la Biblia y de la Biblia). Homenaje de colegas y discípulos a J. Severino Croatto, Buenos Aires, LUMEN-ISEDET, 2000.

HeISE, Ekkehard, La diaconía de la encarnación como liberación de las iglesias. Un concepto elaborado con el ejemplo de la Congregación Evangélica Alemana en Buenos Aires (Iglesia Evangélica del Río de la Plata), Bovenden, Unitext Verlag, 1995.

KInSLER, Ross y Gloria KinsLer (eds.), God's Economy. Biblical Studies from Latin America, Maryknoll, New York, Orbis Books, 2005.

KrÜGER, René, Pobres y ricos en la epístola de Santiago. El desafío de un cristianismo profético, Buenos Aires, Lumen, 2005.

KrÜGER, René, Dios o el Mamón. Análisis semiótico del proyecto económico y relacional del Evangelio de Lucas, Buenos Aires, Lumen, 2009.

Krüger, René, Severino Croatto y Néstor Míguez, Métodos Exegéticos, Buenos Aires, ISEDET, 2006.

Patte, Daniel (ed.), Global Bible Commentary, Nashville, Abingdon Press, 2004.

Schoenborn, Ulrich (ed.), Wege des Verstehens. Beiträge zu einer interkulturellen Hermeneutik, Hermannsburg, Verlag der Missionshandlung Hermannsburg, 2000.

SEgundo, Juan Luis, La liberación de la teología, Buenos Aires / México, Carlos Lohlé, 1975. 
Wegener, Uwe, Exegese do Novo Testamento. Manual de Metodologia, São Leopoldo, Sinodal, 2004.

Wit, Hans, de, "Leyendo con Yael: Un ejercicio en hermenéutica intercultural", en Los caminos inexhauribles de la Palabra. (Las relecturas creativas en la Biblia y de la Biblia). Homenaje de colegas y discípulos a J. Severino Croatto, Guillermo Hansen (ed.), Buenos Aires, LuMEN-ISEDET, 2000, 11-66.

Wit, Hans, de, En la dispersión el texto es patria. Introducción a la hermenéutica clásica, moderna y posmoderna, San José, Costa Rica, Universidad Bíblica Latinoamericana, 2002. 